\title{
Cnidarian phylogenetic relationships as revealed by mitogenomics
}

Ehsan Kayal ${ }^{1,2^{*}}$, Béatrice Roure ${ }^{3}$, Hervé Philippe ${ }^{3}$, Allen G Collins ${ }^{4}$ and Dennis V Lavrov ${ }^{1}$

\begin{abstract}
Background: Cnidaria (corals, sea anemones, hydroids, jellyfish) is a phylum of relatively simple aquatic animals characterized by the presence of the cnidocyst: a cell containing a giant capsular organelle with an eversible tubule (cnida). Species within Cnidaria have life cycles that involve one or both of the two distinct body forms, a typically benthic polyp, which may or may not be colonial, and a typically pelagic mostly solitary medusa. The currently accepted taxonomic scheme subdivides Cnidaria into two main assemblages: Anthozoa (Hexacorallia + Octocorallia) - cnidarians with a reproductive polyp and the absence of a medusa stage - and Medusozoa (Cubozoa, Hydrozoa, Scyphozoa, Staurozoa) - cnidarians that usually possess a reproductive medusa stage. Hypothesized relationships among these taxa greatly impact interpretations of cnidarian character evolution.

Results: We expanded the sampling of cnidarian mitochondrial genomes, particularly from Medusozoa, to reevaluate phylogenetic relationships within Cnidaria. Our phylogenetic analyses based on a mitochogenomic dataset support many prior hypotheses, including monophyly of Hexacorallia, Octocorallia, Medusozoa, Cubozoa, Staurozoa, Hydrozoa, Carybdeida, Chirodropida, and Hydroidolina, but reject the monophyly of Anthozoa, indicating that the Octocorallia + Medusozoa relationship is not the result of sampling bias, as proposed earlier. Further, our analyses contradict Scyphozoa [Discomedusae + Coronatae], Acraspeda [Cubozoa + Scyphozoa], as well as the hypothesis that Staurozoa is the sister group to all the other medusozoans.

Conclusions: Cnidarian mitochondrial genomic data contain phylogenetic signal informative for understanding the evolutionary history of this phylum. Mitogenome-based phylogenies, which reject the monophyly of Anthozoa, provide further evidence for the polyp-first hypothesis. By rejecting the traditional Acraspeda and Scyphozoa hypotheses, these analyses suggest that the shared morphological characters in these groups are plesiomorphies, originated in the branch leading to Medusozoa. The expansion of mitogenomic data along with improvements in phylogenetic inference methods and use of additional nuclear markers will further enhance our understanding of the phylogenetic relationships and character evolution within Cnidaria.
\end{abstract}

Keywords: Cnidaria, Medusozoa, Acraspeda, Anthozoa, mito-phylogenomics

\section{Background}

The phylum Cnidaria encompasses five classes: Anthozoa, Cubozoa, Hydrozoa, Scyphozoa, and Staurozoa. Anthozoa is the most speciose of these classes and is further subdivided into two diverse subclasses Hexacorallia (hard corals and sea anemones) and Octocorallia (soft corals, sea pens, and gorgonians) [1,2]. The remaining four classes -

\footnotetext{
* Correspondence: kayale@si.edu

${ }^{1}$ Dept. Ecology, Evolution, and Organismal Biology, lowa State University, Ames, lowa 50011, USA

${ }^{2}$ Department of Invertebrate Zoology, National Museum of Natural History, Smithsonian Institution, Washington,

DC 20013-7012, USA

Full list of author information is available at the end of the article
}

Cubozoa (box jellies or sea wasps), Hydrozoa (hydras, hydroids, hydromedusae, and siphonophores), Scyphozoa (true jellyfish), and Staurozoa (stalked jellyfish) - are united in the subphylum Medusozoa. Cubozoa (Werner 1975) and Staurozoa (Marques and Collins 2004) were originally included in the class Scyphozoa (Götte 1887), but each has been promoted to the status of class, leaving three orders Coronatae, Rhizostomeae and Semaeostomea in Scyphozoa [1]. Recent progress in understanding cnidarian phylogeny, particularly efforts from the Cnidarian Tree of Life (CnidToL) project (cnidtol.com), based on analyses of rRNA data, have yielded a relatively widely accepted view of cnidarian relationships (Figure 1A). Nevertheless, these

\section{Biomed Central}




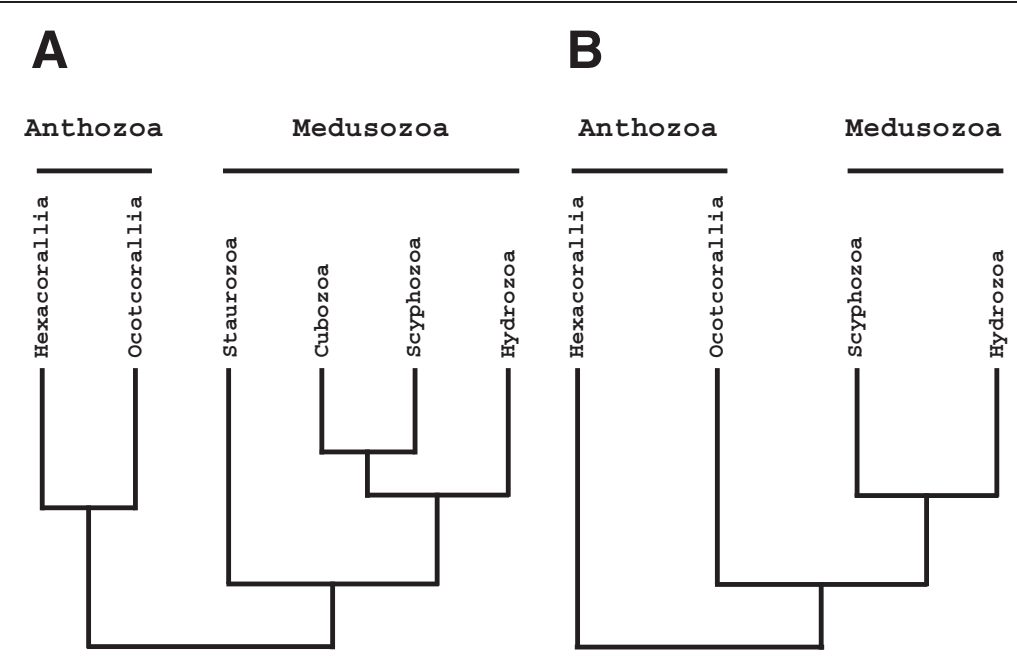

Figure 1 Alternative hypotheses of the cnidarian tree of life. A. Current view of cnidarian evolutionary history based on rRNA phylogenies. B. Hypothesis of cnidarian relationships obtained using mitochondrial protein coding genes.

relationships are hypothetical and subject to tests with alternative datasets, and questions about the relationships among and within the major cnidarian taxa remain.

For instance, monophyly of Anthozoa is supported by numerous analyses of rRNA data [3-6], although only one of them [7] included a dense sampling of both anthozoan and medusozoan taxa. However, studies based on mitochondrial DNA data suggest that Anthozoa is paraphyletic, with octocorals forming a sister group relationship with medusozoans [8-11] (Figure 1B). The monophyly of Medusozoa has not been challenged, but relationships within it remain somewhat contentious. As an example, although traditionally box jellies (Cubozoa) were considered to be closely related to true jellyfish (Acraspeda; Gegenbaur 1856; in accordance with rRNA-based analyses), some studies have suggested the groupings of [Cubozoa + Staurozoa] and [Hydrozoa + Scyphozoa] [12,13]. Furthermore, the early branching position of Staurozoa, as sister group to the remaining medusozoans only received moderate support in rRNA studies [14].

Even within the major cnidarian taxa, phylogenetic hypotheses remain to be assessed with independent datasets. Some studies have nested the monophyletic rhizostome jellyfish within a paraphyletic Semaeostomeae [7,14-16], a view supported by the most recent phylogenetic study using rRNA sequences [17]. Other relevant findings include the sister group relationships between Trachylina and Hydroidolina within Hydrozoa [14], paraphyletic "Filifera" (Kühn 1913) within Hydroidolina [18,19]; monophyletic stony corals (Scleractinia) within Hexacorallia $[20,21]$ in opposition to earlier studies [22]; and, two robust clades Carybdeida and Chirodropida composing box jellyfish (Cubozoa) [23]. In addition, rDNA-based studies have also exposed some disparities between classical taxonomy and molecular phylogenies for some groups [24] and were unable to resolve phylogenetic relationships within others, e.g. Hydroidolina [14,19] and alcyonacean octocorals [24]. Thus, additional markers are necessary to achieve a better understanding of cnidarian relationships.

Resolving phylogenetic relationships for the phylum Cnidaria is a prerequisite for the reconstruction of the evolutionary history of key morphological novelties in this group, e.g. life history and morphological characters $[14,18,25]$, medusan morphospace and swimming ability [26], the evolution of toxicity in cubozoans [23], the origin and evolution of reef-building corals [20,21], and mitochondrial genome structures [27]. One critical character in cnidarian evolution is the ancestral state of the adult life stage, polyp or medusa, which has been a matter of controversy for over a century $[14,28]$. All anthozoans (hexacorals and octocorals) lack a free-living medusa stage, while cubozoans and most scyphozoans contain both polyp and medusa stages. Hydrozoans display the widest range of diversity in their life cycle, with the absence of a sessile polyp in Trachymedusae (which may be diphyletic [29]) and many species of Narcomedusae, and a highly reduced or absent medusa in other lineages (e.g. some clades within Leptothecata and Aplanulata, including the freshwater hydras (Hydridae)) [1,7,18,30,31]. While some earlier studies have proposed the medusa form has been lost in Anthozoa, the current view holds the medusa is an apomorphy (derived character) for Medusozoa [1,14]). Consequently, it is generally considered that (1) a sessile polyp-like form was the ancestral adult form in the phylum Cnidaria and, (2) an adult pelagic medusa phase evolved (one or several times) in Medusozoa [1,14]. However, the latter view has only slight phylogenetic support in the currently accepted cnidarian phylogeny, where the most parsimonious scenario involves the gain of the polyp form in the ancestral Cnidaria and of the medusa form in 
Medusozoa. Alternatively, both the polyp and the medusa forms could have been acquired in the ancestral cnidarian, and the medusa form subsequently lost in the branch leading to Anthozoa. The multiple losses of the medusa stage in different medusozoan lineages suggest that this character is indeed evolutionary labile.

Medusozoa (sometimes referred to as Tesserazoa) is supported by a combination of characters both morphological (e.g. presence of an adult pelagic stage, cnidocils (cilia of cnidocytes lacking basal rootlets), and microbasic eurytele nematocysts) and molecular (e.g. rDNA, mitochondrial protein genes, linear mitochondrial DNA) [1,14,28]. Similarly, several morphological characters have been suggested as synapomorphies for Anthozoa, including the presence of an actinopharynx (a tube leading from the mouth into the coelenteron), mesenteries and possibly siphonoglyphs (ciliated grooves longitudinally extending along the pharynx), although the latter are absent in some anthozoan lineages [1]. As noted above, conflicting evidence exists about the monophyly of Anthozoa, being supported by rRNA data [3-6] (Figure 1A) and contradicted by mitochondrial genome DNA data [8-11] (Figure 1B). This alternative phylogenetic hypothesis, if true, would necessitate reinterpretation of morphological characters shared by anthozoans as symplesiomorphies (retained from the common ancestor) rather than synapomorphies.

Mitochondrial DNA (mtDNA) is a popular molecular marker for understanding the phylogenetic relationships in animals. Recent technological advances in sequencing complete mtDNA sequences have provided easier access to mitogenomic data for phylogenomic studies [32-34]. Some suggested advantages of mtDNA over nuclear DNA (nDNA) in phylogenetics are the asserted orthology of all genes [35] and the small genome structure being relatively conserved, which provides additional characters such as gene order (considered as Rare Genetic Changes or RGC) [36,37]. Despite some limitations, mtDNA-based phylogenetic trees are considered valid proxies of the evolutionary history within and between most metazoan groups. In non-bilaterian animals, recent increase in the number of completely sequenced mtDNAs has helped to resolve deep phylogenetic nodes within sponges $[9,38]$ and Hexacorallia within Cnidaria [22,39]. Yet, the very poor sample size of medusozoan taxa in previous studies raises some question about the validity of phylogenetic results based on them. Indeed, it is known that inadequate taxon sampling and systematic errors can override genuine phylogenetic signal, resulting in flawed phylogenetic reconstructions $[40,41]$.

We assembled a more taxonomically balanced mitogenomic dataset to investigate the evolutionary history of cnidarians. Our dataset contains newly published mitochondrial sequences from 24 representative species of all medusozoan classes, including three orders of
Scyphozoa, both orders of Cubozoa, and six out of the nine orders of Hydrozoa [27]. We also included sequences from two octocoral orders Penatulacea and Helioporacea, and two hexacoral orders Antipatharia and Ceriantharia. Our analyses suggest that the paraphyly of Anthozoa does not result from poor taxon sampling. We also found the groupings [Discomedusae + Hydrozoa] and [Coronatae + [Cubozoa + Staurozoa]], contradicting the current rDNAbased phylogenetic hypothesis within Medusozoa.

\section{Results}

Additional mitogenomes for Hexacorallia and Octocorallia For this study, we amplified and sequenced the complete mtDNA of the black coral Cirripathes lutkeni (20,448 bp), the sea pens Renilla muelleri (18,643 bp) and Stylatula elongata (18,733 bp), and the alcyonarian Sinularia peculiaris (18,742 bp) as described earlier [27] and partial mt sequences for the cerianthid Ceriantheopsis americanus and the octocoral Heliopora coerulea. All three complete octocoral mt-genomes have the same genome organization as that of Sarcophyton glaucum. The mtDNA of C. lutkeni is similar to that of Chrysopathes formosa, but possesses an intron within coxl that harbors a HEG-like ORF, responsible for the larger genome size. Partial data from the mtDNA of $C$. americanus does not allow us to discuss the mitochondrial genome organization in Ceriantharia.

\section{Models of sequence evolution in our phylogenetic analyses}

We evaluated how the site-heterogeneous CAT and CATGTR models perform on mitochondrial protein amino acid dataset (AliMG) compared to the reference site-homogeneous model GTR under BI by using crossvalidation. According to pair-wise difference of loglikelihood scores, we found that the CATGTR model more accurately explained our data $(330.78+/-40.071)$; the CAT model was the worst of the three models for our alignment $(-111.61+/-63.337)$. For all the codon alignments, we found GTR to be the best-fit model according to the Bayesian Information Criterion (BIC), the corrected Akaike Information Criterion (AICc), and the Decision Theory Performance-Based selection (DT). We therefore used the GTR models as well as the Q-Matrix Mixture model (QMM) implemented in PB for all codon analyses.

\section{Phylogenetic relationships among cnidarian classes}

We analyzed the phylogenetic relationships among cnidarian classes for both the amino acids and codon data under the Bayesian (BI) and the Maximum Likelihood (ML) frameworks. We also used two different models of sequence evolution (GTR and CATGTR) for Bayesian inferences on the amino acids alignment. For all our analyses, we decided to exclude sequences from bilaterian animals because they form long branches in mitochondrial 
phylogenomic trees that attract other long branches, resulting in Long Branch Attraction artifacts [42,43]. In the future, the inclusion of bilaterians in mtDNA-based phylogenies can be tested given better models of sequence evolution are available. We found maximum support for the monophyly of Medusozoa, Cubozoa, Staurozoa, Hydrozoa, and Discomedusae in all amino acid analyses (Table 1). In the analyses based on amino acid sequences, a few

Table 1 Support values for topologies in the mtDNA-based phylogeny of cnidarians

\begin{tabular}{|c|c|c|c|}
\hline & & AliMG & \\
\hline Taxon & GTR-ML & GTR-BI & CATGTR \\
\hline Cnidaria & 12 & 0 & 1 \\
\hline Anthozoa & 0 & 0 & 0 \\
\hline Hexacorallia & 12 & 0.22 & 0.57 \\
\hline Antipatharia & 100 & 1 & 1 \\
\hline Actiniaria & 100 & 1 & 1 \\
\hline Corallimorpharia & 100 & 1 & 1 \\
\hline Scleractinia & 12 & 0 & 0.51 \\
\hline Zoantharia & 100 & 1 & 1 \\
\hline Octocorallia & 100 & 1 & 1 \\
\hline Alcyonacea & 7 & 0 & 0.01 \\
\hline Pennatulacea & 96 & 1 & 1 \\
\hline Medusozoa & 100 & 1 & 1 \\
\hline Acraspeda & 0 & 0 & 0 \\
\hline Cubozoa & 100 & 1 & 1 \\
\hline Carybdeida & 99 & 1 & 1 \\
\hline Chirodropida & 100 & 1 & 1 \\
\hline Hydrozoa & 100 & 1 & 1 \\
\hline Aplanulata & 100 & 1 & 1 \\
\hline Capitata & 95 & 1 & 1 \\
\hline Scyphozoa & 0 & 0 & 0 \\
\hline Discomedusae & 100 & 1 & 1 \\
\hline Rhizostomeae & 11 & 0 & 0.14 \\
\hline Semaeostomeae & 0 & 0 & 0 \\
\hline Staurozoa & 100 & 1 & 1 \\
\hline Placozoa & 100 & 1 & 1 \\
\hline Porifera & 100 & 1 & 0.88 \\
\hline Homoscleromorpha & 100 & 1 & 1 \\
\hline Demospongiae & 100 & 1 & 1 \\
\hline Keratosa & 100 & 1 & 1 \\
\hline Myxospongiae & 100 & 1 & 1 \\
\hline marine Haplosclerida & 100 & 1 & 1 \\
\hline Democlavia & 100 & 1 & 1 \\
\hline
\end{tabular}

Bootstraps values (for GTR-ML) and posterior probabilities (for GTR and CATGTR-BI) obtained for the AliMG alignment for several clades traditionally recognized in Cnidaria. differences emerged when using two different models of sequence evolution, most of them limited to poorly supported branches. For instance, we found monophyletic Cnidaria (posterior probability $\mathrm{PP}=1$ ) and Hexacorallia (but with no support PP $=0.57$ ), and the placement of the coronate Linuche unguiculata as the sister taxa to the clade [Cubozoa + Staurozoa] $(\mathrm{PP}=0.56)$ under the CATGTR model (Figure 2). On the other hand, we found paraphyletic Cnidaria and Hexacorallia in all GTR trees, where the position of Ceriantheoptsis americanus was unstable (data not shown). We also observed that $L$. unguiculata was the first diverging medusozoan clade in GTR (BI) analyses but the sister taxa to [Cubozoa + Staurozoa] in GTR (ML) without support (bootstraps $\mathrm{BV}=20$ ). Removing the coronate $L$. unguiculata and those species with missing data (the blue coral Heliopora coerulea and the tube anemone C. americanus) did not impact cnidarian paraphyly under GTR (ML) model (Additional file 1: Figure S1).

All analyses supported the clade [Octocorallia + Medusozoa] (CATGTR: PP = 1; GTR: PP = 0.98; BV = 54), although posterior probabilities (PP) were lower when GTR model was used (Figure 2). Within Medusozoa, we recovered the monophyly of Cubozoa, Staurozoa, and Hydrozoa with maximum support, but Scyphozoa [Coronatae + Discomedusae] was not recovered as a monophyletic group in any analyses (Table 1). The class Hydrozoa always grouped with Discomedusae (CATGTR: $\mathrm{PP}=1$; GTR: $P P=1 \mathrm{BV}=89$ ), and Cubozoa was the sister taxon to Staurozoa (CATGTR: PP $=0.83$; GTR: $\mathrm{PP}=1 \mathrm{BV}=58$ ). When we removed the single species of coronate, $L$. unguiculata, the support values for the clade [Cubozoa + Staurozoa] slightly increased $(B V=85)$, while support values for the clade [Hydrozoa + Discomedusae] decreased $(\mathrm{BV}=66)$.

We also analyzed codon alignments from a subset of 75 species using the GTR and the QMM models under BI and the GTR model under the ML frameworks. It has been shown that codon usage bias can result in phylogenetic artifact [44]. In order to minimize the impact of codon usage bias on phylogenetic trees, we reanalyzed the codon dataset after removing the third codon position, as well as codons for arginine (AGR and CGN), leucine (CTN and $\mathrm{ATH}$ ), and serine (TCN and AGY). Only the CodAliM75tx-argleuser3 dataset under GTR and the CodAliM75tx-argleuser3 and the CodAliM75tx-ser3 datasets under QMM model produced informative trees (Additional file 2: Figures S2 and Additional file 3: Figure S3), the other analyses resulting in the near absence of phylogenetic resolution. When some resolution was achieved, the codon analyses yielded similar results to those from the amino acid dataset. We found paraphyletic Anthozoa, with Medusozoa the sister taxon to Octocorallia $(\mathrm{PP}>0.95)$ in all codon analyses, but monophyletic 


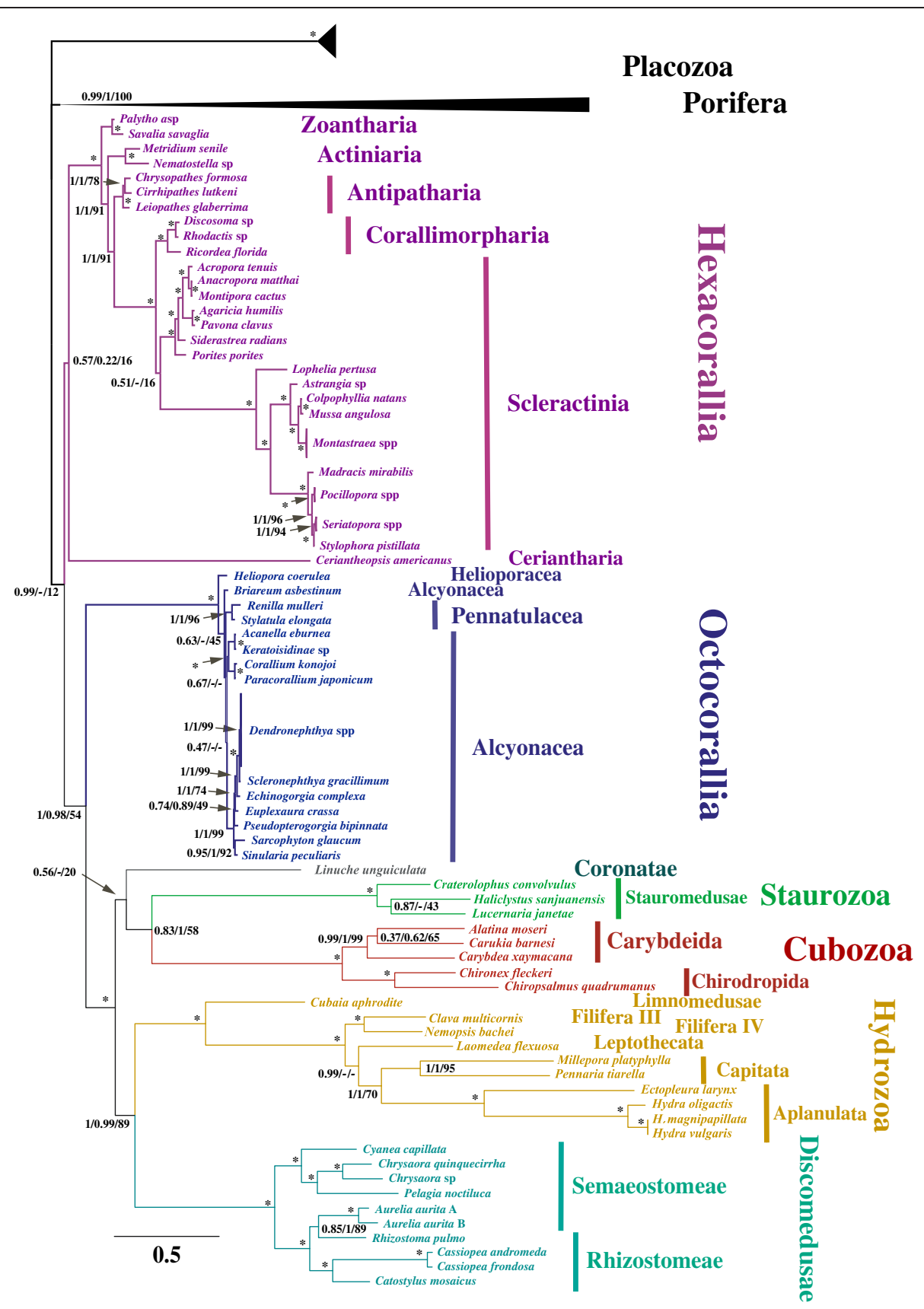

Figure 2 Cnidarian phylogenetic hypothesis based on mitochondrial protein genes. Phylogenetic analyses of cnidarian protein coding genes under the CATGTR model with PhyloBayes for the AliMG alignment (3111 positions, 106 taxa) created using the MUSCLE plug-in in Geneious and filtered using Gblock. Support values correspond to the posterior probabilities for the CATGTR(BI) and GTR(BI), and bootstraps for GTR(ML) analyses. Stars denote maximum support values. A dash denotes discrepancy between the results obtained when assuming different models.

Cnidaria only in the QMM analysis of the CodAliM75txser3 dataset $(\mathrm{PP}=0.85$, Additional file 3: Figure S3).

\section{Intra-class relationships}

Within Discomedusae, our data reject the monophyly of Semaeostomeae and Rhizostomeae (Table 1) with the rhizostome Rhizostoma pulmo as the sister taxon to the ulmariid semaeostome Aurelia aurita, while uniting the semaeostome families Cyaneidae and Pelagiidae, as well as all the remaining rhizostomes. Cubozoa is divided into the two monophyletic clades Carybdeida and Chirodropida as found earlier [23], but our data do not resolve the relationships between the three carybdeids. In Hydrozoa, our analyses supported the dichotomy Trachylina (Cubaia aphrodite) - Hydroidolina (the rest of the hydrozoans) with high support values (PPs $=1$; BVs $=100$; Figure 2). 
The aplanulatan Hydra spp and Ectopleura larynx and the capitates Millepora platyphylla and Pennaria disticha formed a monophyletic clade (PPs $=1 ; B V=70)$. The species Clava multicornis (Filifera III) and Nemopsis bachei (Filifera IV) also formed a monophyletic clade as the sister group to the rest of Hydroidolina with maximum support values. The position of the leptothecate Laomedea flexuosa was different between GTR and CATGTR analyses. The GTR trees placed Leptothecata as the sister taxon to the clade [Filifera III + Filifera IV] $(\mathrm{PP}=1$; $\mathrm{BV}=86)$ similar to $\mathrm{ML}$ analyses using nuclear and mitochondrial rRNA genes with the GTRMIX model of sequence evolution [18]. By contrast, Bayesian analysis using the CATGTR model strongly supported the leptothecate hydrozoan as the sister taxon to the clade [Aplanulata + Capitata] $(\mathrm{PP}=0.99)$.

Our data do not resolve the position of Ceriantharia (tube anemones). Given that our sequence for the tube anemone is incomplete and our sampling only includes one species from Ceriantharia, additional data from the group might provide some clues on the position of cerianthids. We recovered the currently accepted order-level relationships [20] for the remaining hexacorals in all our analyses (Figure 2). Zoanthidea (zoanthids) was the earliest diverging lineage, followed by Actiniaria (sea anemones), Antipatharia (black corals), and the clade [Corallimorpharia + Scleractinia]. The order Scleractinia (stony corals) was monophyletic in CATGTR analyses with low support values $(\mathrm{PP}=0.51$ ), but paraphyletic under GTR framework, where one clade of scleractinians was the sister taxa to corallimorphs $(\mathrm{PP}=1 ; \mathrm{BV}=92)$. Finally, despite the addition of two new sequences from Pennatulacea (Renilla muelleri and Stylatula elongata) and partial data from Heliopora coerulea, our analyses did not resolve the phylogenetic relationships within Octocorallia.

\section{Testing evolutionary hypotheses}

We used several phylogenetic tests to evaluate the support for traditional taxonomic hypotheses of our datasets under the ML framework. We used the Approximately Unbiased (AU) test, the Kishino-Hasegawa (KH) test, and the Shimodaira-Hasegawa (SH) test with the GTR $+\Gamma$ model (Table 2). We found that the order Semaeostomeae is significantly rejected ( $\mathrm{AU}=0.01 ; \mathrm{KH}=0.02 ; \mathrm{SH}=0.18)$, but not the inclusion of staurozoan species as part of an extensive "Scyphozoa" clade $(\mathrm{AU}=0.01 ; \mathrm{KH}=0.04 ; \mathrm{SH}=0.25)$. We also found that despite the absence of support for the monophyly of both Hexacorallia and Scleractinia in GTR trees, hypothesis tests do not reject these clades (Table 2). In addition, GTR-based analyses do not significantly reject the validity of Anthozoa ( $\mathrm{AU}=0.63 ; \mathrm{KH}=0.41 ; \mathrm{SH}=0.93$ ), Scyphozoa ( $\mathrm{AU}=0.10 ; \mathrm{KH}=0.08 ; \mathrm{SH}=0.42)$, or the clade Acraspeda [Cubozoa + Scyphozoa] ( $\mathrm{AU}=0.80 ; \mathrm{KH}=0.59$; $\mathrm{SH}=0.99$ ), even after removal of the long-branch coronate
Table 2 The use of several statistical tests verifying the validity of some groups in cnidarians

\begin{tabular}{lccc}
\hline & \multicolumn{3}{c}{ AliMG } \\
\cline { 2 - 4 } & AU & KH & SH \\
\hline Cnidaria & 0.27 & 0.15 & 0.86 \\
Anthozoa & 0.63 & 0.41 & 0.93 \\
Hexacorallia & 0.48 & 0.32 & 0.86 \\
Scleractinia & 0.25 & 0.17 & 0.53 \\
Acraspeda* & 0.80 & 0.59 & 0.99 \\
Rhizostomeae & 0.24 & 0.17 & 0.64 \\
Scyphozoa & 0.10 & 0.08 & 0.42 \\
Scyphozoa + Cubozoa + Hydrozoa* & 0.12 & 0.14 & 0.41 \\
Scyphozoa + Cubozoa + Staurozoa* & 0.04 & 0.01 & 0.27 \\
Scyphozoa + Staurozoa* & 0.01 & 0.04 & 0.25 \\
Semaeostomeae & 0.01 & 0.02 & 0.18 \\
\hline
\end{tabular}

Probability values for the $\mathrm{AU}, \mathrm{KH}$ and $\mathrm{SH}$ tests and $\mathrm{BI}$ values for several clades traditionally recognized in Cnidaria.

* similar results have been obtained for a smaller dataset that does not contain the sequences from the coronate Linuche unguiculata, the tube anemone Ceriantheopsis americanus and the blue octocoral Heliopora coerulea.

L. unguiculata $(\mathrm{AU}=0.75 ; \mathrm{KH}=0.66 ; \mathrm{SH}=0.90$; Additional file 4:Figure S4). By comparison, under BI we found no support for the validity of Anthozoa (PPs $=0 ; B V=0$ ), Acraspeda (PPs $=0 ; \mathrm{BV}=0)$, Scyphozoa $(\mathrm{PPs}=0 ; \mathrm{BV}=0)$, and Semaeostomeae $(\mathrm{PPs}=0 ; \mathrm{BV}=0)$ in any of our trees under both GTR and CATGTR models.

\section{Discussion}

We reevaluated cnidarian phylogenetic relationships using a dataset of mitochondrial protein genes from a systematically more balanced sample of species, including cubozoans and staurozoans [27], which were absent in previous works $[10,12]$. Our cnidarian-rich dataset reduced one major source of potential error that could derive from biased and insufficient taxon sampling for the groups of interest. In our analyses, the site-heterogeneous model CATGTR recovered the monophyly of Cnidaria and Hexacorallia, both supported by molecular and morphological characters [12,45-49]. By contrast, these clades were paraphyletic in both Maximum Likelihood and Bayesian analyses based on the GTR model of sequence evolution. This is not surprising given that a main assumption underlying the GTR model, i.e. homogeneity of the substitution pattern across sites, is violated by most molecular data, rendering the correct capture of the phylogenetic signal present in our alignments more difficult [50]. The resulting topologies from CATGTR analyses differed significantly from the current consensus view of cnidarian phylogeny $[1,2]$. Using the best estimate as a working hypothesis for cnidarian relationships, we can propose a putative reconstruction of character evolution for the group. 
The mitogenomic point of view of cnidarian systematics

The current view on cnidarian phylogeny based on nuclear rRNA genes subdivides the phylum Cnidaria into Anthozoa and Medusozoa [1,2], but mitochondrial protein genes have consistently supported anthozoan paraphyly with Octocorallia being the sister taxon to Medusozoa [8-11]. It has been argued that the paraphyly of Anthozoa reported in earlier mitogenomic studies resulted from poor taxon sampling $[2,10]$. Here we show that paraphyletic Anthozoa does not result from unbalanced taxon sampling. In addition, a principal component analysis of the amino acid composition (Additional file 5: Figure S5) suggests that compositional bias is also an unlikely explanation. The amino acid composition of Hexacorallia is rather divergent, but not similar to those of the two outgroups (Porifera and Placozoa); in fact, the composition similarity between Octocorallia and the outgroups would favor the alternative possibility of Anthozoa paraphyly [Medusozoa + Hexacorallia], which is not observed in our analyses. To further test the possible impact of compositional bias, we analyzed our alignments using the CATGTR model with a Dayhoff recoding strategy, despite the fact that it implies a loss of signal resulting in increasing the stochastic error. Interestingly, Octocorallia remained sister-group of Medusozoa, even if the statistical support was reduced (data not shown).

We also analyzed codon alignments using the GTR and QMM models under Bayesian and GTR under Maximum Likelihood frameworks. Even after removing the third position as well as codons for arginine (AGR and CGN), leucine (CTN and ATH), and serine (TCN and AGY), which can cause phylogenetic artifacts [44], we found the paraphyly of Anthozoa, with Medusozoa the sister taxon to Octocorallia (Additional file 2: Figure S2 and Additional file 3: Figure S3). Consequently, according to our analyses, mitochondrial protein genes support the clade [Octocorallia + Medusozoa] (Figure 2). In contrast, the amino acid composition of Hydrozoa and Discomedusae is similar (Additional file 4: Figure S4) and the Dayhoff recoding recovered Discomedusae as sister-group of Cubozoa (a reduced version of Acraspeda), although with low support, suggesting that the monophyly of the clade [Hydrozoa + Discomedusae] might be due to an amino acid composition artifact. In fact, preliminary analyses including the very fast evolving and compositionally biased Bilateria using the site-heterogeneous CATGTR model supported the unlikely grouping of Bilateria and Cubozoa (data not shown). This suggests that the use of a complex model of sequence evolution and of a rich taxon sampling is not sufficient to overcome all the systematic errors in the mitochondrial protein dataset. With the current increase in genome sequencing efforts, it will soon be possible to evaluate our phylogenetic tree (Figure 2) with large nuclear DNA datasets.
Within Medusozoa, Staurozoa is considered the first diverging clade, and the sister taxon to [Acraspeda (Cubozoa + Scyphozoa) + Hydrozoa] (reviewed in [2]). While the position of Linuche unguiculata is still ambiguous in our trees, we found no support for either the inclusion of coronates in Scyphozoa (PPs $=0$; BV $=0$ ), or for Acraspeda [Cubozoa + Scyphozoa] (PPs = 0; BV = 0). Instead, we found high support for the clades [Hydrozoa + Discomedusae] $(\mathrm{PPs}=1 ; \mathrm{BV}=89)$ and [Cubozoa + Staurozoa] (CATGTR: $\mathrm{PP}=0.83 ; \quad$ GTR: $\mathrm{PP}=1 ; \quad \mathrm{BV}=58$ ). This suggests that Scyphozoa is polyphyletic, although both Scyphozoa and Hydrozoa display similar amino acid composition. Additional sequences from coronates are needed to test the phylogenetic relationships presented here.

Recent molecular studies have refined our understanding of hydrozoan relationships, particularly the sister group relationship between Hydroidolina and Trachylina [7,14,18,19,30,51]. However, relationships within Hydroidolina have been very difficult to resolve based on either nuclear or mitochondrial rDNA genes. Here we have been able to sample five important hydroidolinan clades: Aplanulata, Capitata, Filifera III and IV, Leptothecata, and Limnomedusae. Mitochondrial protein genes provide good resolution for order-level relationships within Hydrozoa, although our sampling was limited in scope (only 10 species representing 6 out of 11 orders; Figure 2). We recovered monophyletic Hydroidolina as the sister group to our single representative from Trachylina. We also found monophyletic Aplanulata and Capitata, and paraphyletic Anthoathecata as suggested earlier $[14,18]$. On the other hand, we found a consistent grouping of capitate and aplanulate hydrozoans in all our trees (PPs $=1$; BV $=88$ ), which is in contradiction with earlier rDNAbased studies [7,18,19,29,30,49,51]. The high support values here suggest that higher resolution of the clade Hydroidolina may be achieved with an increase in the number of complete mtDNAs for representative taxa within this difficult clade.

Based on mitochondrial genome data, the monophyly of stony corals (Scleractinia) has recently been put into question [22], but more thorough studies employing alternative datasets have rejected this hypothesis [21,52]. Our analyses support the monophyly of Scleractinia under the preferred CATGTR model $(\mathrm{PP}=0.51 ; \mathrm{AU}=0.25$; $\mathrm{KH}=0.17 ; \mathrm{SH}=0.53$ ). Our phylogenetic analyses did not resolve relationships within octocorals. This was predictable given the low-level of variation of mitochondrial genes in octocorals (see [53]), a pattern attributed to the activity of the $m t M u t S$ gene they encode. It is noteworthy mentioning that our alignments did not encompass sequences from the $m t M u t S$ gene, absent in all other cnidarian and animal taxa, and which displays a comparatively higher rate of sequence evolution than other genes [54]. While future molecular studies of the evolutionary history of octocorals 
may focus their investigation to only a portion of the mtDNA [55], complete mitogenomes provide additional genomic features such as gene order and the composition of intergenic regions (IGRs) that could be valuable to systematic studies [10]. Furthermore, the combination of mitogenomic sequences with nuclear data will likely provide even better phylogenetic resolution for this group.

\section{Morphological evolution in cnidarians}

Unlike the dichotomous Anthozoa-Medusozoa, our strongly supported finding that Anthozoa is paraphyletic further supports the idea that bilateral symmetry, a step of foremost importance in metazoan evolution as it is exhibited as part of most animal body plans (Bauplan), was anciently acquired prior to the divergence between Cnidaria and Bilateria. In fact in Cnidaria, increasing evidence supports the presence of bilateral symmetry in corals and sea anemones, where it is represented by the siphonoglyph $[56,57]$, while most medusozoans do not exhibit any bilateral symmetry $[28,58]$, with siphonophores being an exception [59]. The tree topologies provided here strengthen the view that the ancestral cnidarian displayed a bilateral symmetry from which the radial tetrameral symmetry (body divided into four identical parts) of most medusae and many polyps of medusozoans derived (Figure 3). Previous studies have already suggested

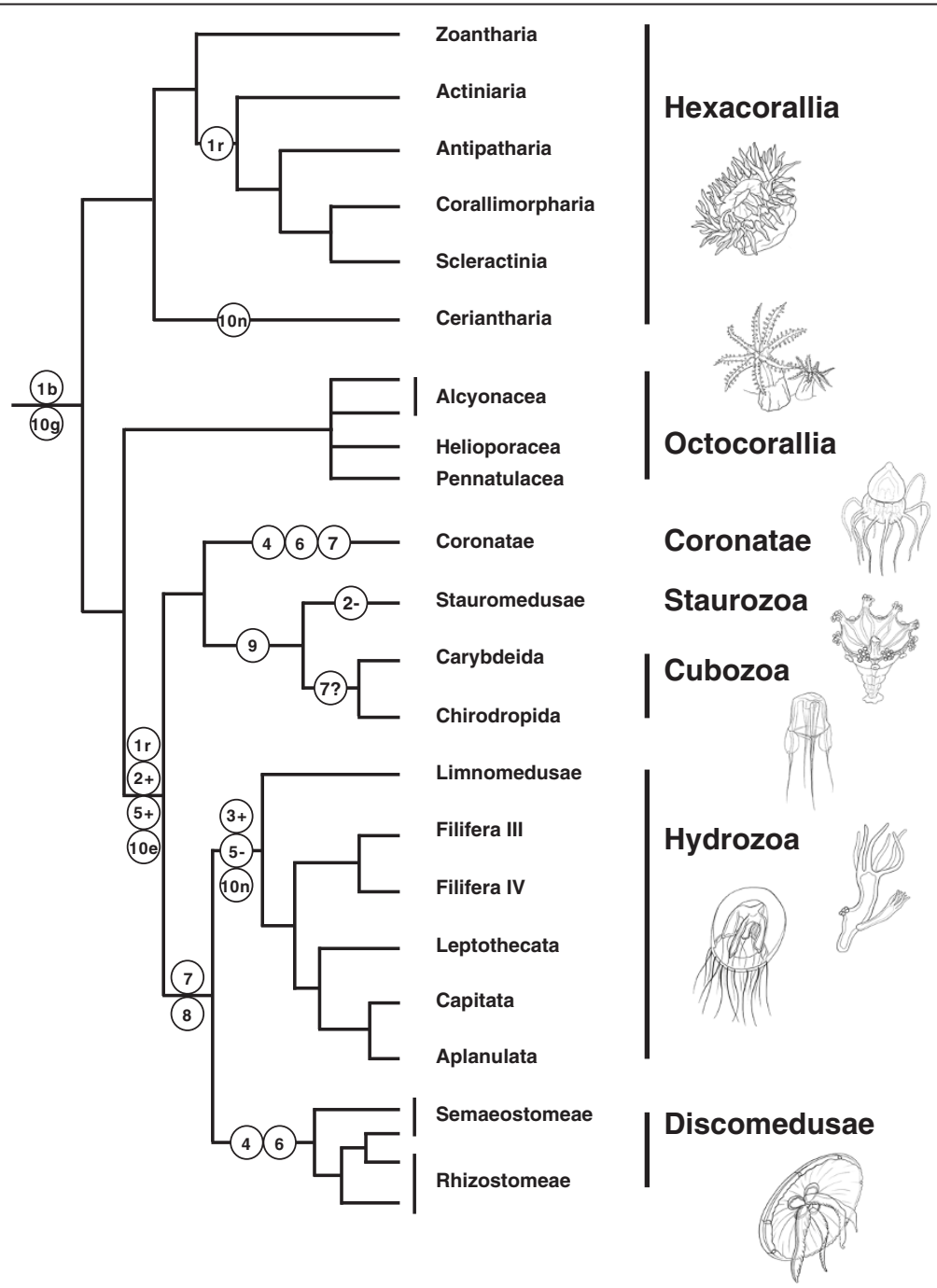

Figure 3 Morphological character reconstruction in Cnidaria. Reconstruction of key morphological characters in Cnidaria based on the phylogenetic hypothesis based on mitogenomic data. (1) symmetry: $b=$ bilaterial, $r=$ radial or biradial; (2) gain (+) and loss (-) of free-swimming medusoid stage (many hydrozoans have secondarily lost the medusoid phase); (3) velum (lost in some leptothecate hydrozoans); (4) strobilation; (5) gastric filaments; (6) ephyrae; (7) radial canal (scored uncertain in Cubozoa); (8) circular canal; (9) square symmetry of horizontal cross section; (10) gastrodermal muscles: $\mathrm{e}=$ in bunches of ectodermal origin, $\mathrm{g}=$ in bunches of gastrodermal origin, $\mathrm{n}=$ not organized in bunches. Morphological characters are taken from Marques and Collins (2004) and Cartwright and Nawrocki (2010) studies. Drawings were provided by Matthew Palen. 
occurrences of deviation from a bilateral Bauplan in several animal groups, such as siphonophores [59], myxozoans [60] and some bilaterians [61,62]. Bilaterality has evolved very early in animal evolution near the root of the metazoan tree [63], and our data support the view that such a step was taken before the divergence of Cnidaria. Future studies that resolve the position of cnidarians within the metazoan tree of life will shed light on the origin of bilateral symmetry in animals.

Based upon the basal position of Staurozoa in previous phylogenies, Collins and collaborators [14] proposed that the medusa of Hydrozoa, Cubozoa and Scyphozoa derived from a stauromedusa-like ancestor. However, if the mitogenomic hypothesis of Cnidaria is true (Figure 3), then the free-living medusa form likely evolved in the branch leading to monophyletic Medusozoa, with subsequent independent losses of this life stage occurring in the lineages leading to Staurozoa and several hydrozoan clades (Figure 3). This scenario is consistent with earlier studies that originated the name "stalked jellyfish" for staurozoans, and concluded that these species represented "degenerated" jellyfish descended from ancestors with a pelagic medusa $[14,16,64,65]$. Simplification or losses of the medusa form has also been documented in several Hydrozoa clades [18]. The acquisition of a pelagic form is significant given that a free-swimming medusa allows a higher degree of offspring dispersion than by gametes and larvae alone [66].

Earlier studies have suggested several synapomorphies for the extended Acraspeda clade (Cubozoa + Scyphozoa + Staurozoa), namely radial tetrameral symmetry, medusa formation located at the apical end of the polyp, polyps with canal system and gastrodermal musculature organized in bunches of ectodermal origin (4 inter-radial within the mesoglea in Staurozoa and Scyphozoa, but not limited to 4 in Cubozoa), the presence of rhopalia or rhopalioid-like structures, medusae with gastric filaments and septa in the gastrovascular cavity [28,58]. Paraphyletic Acraspeda as suggested by our analyses implies that either these characters were acquired several times independently in Cubozoa, Coronatae and Discomedusae, or that they have been inherited from the ancestral medusozoan and lost in Hydrozoa. Given the complexity of these characters, it is unlikely that they were re-derived independently in various lineages. Rather, the most parsimonious scenario is their presence in the last common ancestor of medusozoans, with subsequent loss(es) in hydrozoans. Similarly, Scyphozoa are defined by the presence of ephyrae and simple rhopalia, and production of medusae through strobilation of the polyp $[1,14,28,58]$. If Scyphozoa are paraphyletic as suggested by our trees, these characters can be either convergent or plesiomorphic. For instance, rhopalia-like structures are present in all medusozoan clades but Hydrozoa. According to the mitogenomic view of cnidarian phylogeny, the most parsimonious scenario suggests that the ancestral medusozoan possessed some sort of rhopalium, maybe similar to those present in discomedusans and coronates. According to this scenario, simplification of rhopalia must have accompanied the degeneration of the medusae in Staurozoa, while they were completely lost in Hydrozoa. By contrast, the rhopalia in Cubozoa have evolved into complex structures with multiple, complex eyes. Marques and Collins (2004) have suggested a clade formed by [Cubozoa + Staurozoa] based on cladistic analysis of a set of morphological and life-history characters [28]. They suggested the presence of $\mathrm{y}$-shaped septa and a quadrate or square symmetry of horizontal cross-section as synapomorphies for this clade. Mitogenomic data also support such a grouping, providing additional evidence for the validity of these characters as synapomorphies for the clade [Cubozoa + Staurozoa].

\section{Conclusions}

We used an extended dataset of mitochondrial protein genes to reevaluate the phylogeny of Cnidaria, paying attention to common biases in phylogenetic reconstructions resulting from insufficient taxon sampling and using more simplistic models of sequence evolution. Our phylogenetic analyses suggest the grouping of Octocorallia and Medusozoa to the exclusion of Hexacorallia, resulting in paraphyletic Anthozoa. We also recovered the [Discomedusae + Hydrozoa] and [Coronatae + [Cubozoa + Staurozoa]] relationships within Medusozoa. It should be noted, however, that although our data provide little or no support for the clades Anthozoa, Acraspeda and Scyphozoa, they are not rejected with statistically significant support in the maximum-likelihood framework. Using the new mito-phylogenomic view, we reconstructed the evolution of several morphological characters in medusozoans. In particular, our phylogenetic hypothesis provided additional evidence for the "polyp first" theory, where the ancestral cnidarian was a bilateral polyp-like organism, and that a radially symmetrical and vagile medusa evolved in the branch leading to Medusozoa. Our analyses support the view that the ancestor of cnidarians and bilaterians (UrEumetazoa) possessed bilateral symmetry [67]. According to our working hypothesis, synapomorphies traditionally associated with Acraspeda such as the presence of gastric filaments in the medusae and gastrodermal musculature organized in bunches of ectodermal origin were most likely acquired early in the evolution of Medusozoa, and later lost in the branch leading to Hydrozoa. Finally, our study highlights some of the limitations of mt-based phylogenies and call for the concomitant use of several markers for resolving such deep nodes in the metazoan tree of life. 


\section{Methods}

Mitochondrial sequence acquisition and alignment

We determined the complete mitochondrial genome sequences from the black coral Cirripathes lutkeni (NC_018377), the sea pens Renilla muelleri (NC_018378) and Stylatula elongata (NC_018380), the alcyonarian Sinularia peculiaris (NC_018379), as well as partial sequences from the cerianthid Ceriantheopsis americanus (JX023261-JX023265) and the octocoral Heliopora coerulea (JX023267-JX023272) as described previously [27]. In order to understand the phylogenetic signal contained within mitochondrial genomes, we constructed a dataset containing these new sequences, complete or nearly complete mitochondrial sequences from 24 medusozoan species that our group recently generated [27], as well as 51 other sequences previously available in GenBank, using four placozoan and 22 poriferan species (Table 3) as outgroup taxa. Our dataset covered most of the cnidarian diversity with representatives from all medusozoan classes, including cubozoans and staurozoans, which were only recently sampled [27]. The resulting dataset contains 106 taxa, 75 of which are cnidarian species, with representatives from the three Scyphozoa, the two Cubozoa and six of the 11 Hydrozoa orders.

\section{Sequence alignments}

For this study, we focused our attention on the mitochondrial protein coding genes atp6 and 8, cob, cox1-3, nad1-6 and $4 \mathrm{~L}$. First, we created preliminary alignments of the amino acid sequences to correct potential frameshifts in our dataset. We then aligned the amino acid sequences of individual genes using the MUSCLE plug-in in Geneious Pro v5.5.6 [88] with default parameters, and we concatenated all the gene alignments into a single large dataset. We removed poorly aligned regions with Gblocks online (Castresana Lab, molevol.cmima.csic. es/castresana/) with the options allowing gap for all positions and $85 \%$ of the number of sequences for flanking positions. We manually checked the resulting alignment to correct for signs of frameshifts in sequences. The final alignment (AliMG) comprised 3485 amino acids (see Additional file 6).

In order to confirm our results from amino acid data, we also produced and analyzed several codon alignments. From the above 106 taxa list, we selected 75 taxa, including 10 octocorals and 20 hexacorals, to build several codon alignments. First, we create a codon alignment for each gene based on the concatenated amino acid alignment using the program PAL2NAL [89], before concatenating all genes into a single alignment (CodAliM75tx, 9921 parsimony-informative characters). We then created several additional codon alignments by removing the third codon position (CodAliM75tx-3, 5672 parsimony-informative characters); codons encoding for arginine (AGR and CGN) and leucine (CTN and ATH) (CodAliM75tx-argleu3, 5163 parsimony-informative characters); codons encoding for serine (TCN and AGY) (CodAliM75tx-ser3, 5318 parsimony-informative characters); and a combination of all three (CodAliM75tx-argleuser3, 4785 parsimonyinformative characters). All the alignments are available upon request.

We used the program Net from the MUST package [90] to estimate the amino-acid composition per species in each of the alignments by assembling a $20 \mathrm{X} 106$ matrix containing the frequency of each amino acid. This matrix was then displayed as a two-dimensional plot in a principal component analysis, as implemented in the $R$ package.

\section{Phylogenetic inferences}

For the amino acid alignment AliMG, we conducted phylogenetic analyses under Maximum Likelihood (ML) and Bayesian (BI) frameworks using RAxML v7.2.6 and PhyloBayes v3.3 (PB), respectively [50,91-96]. PB analyses consisted of two chains over more than 11,000 cycles (maxdiff < 0.2) using CAT, GTR, and CAT + GTR models, and sampled every 10th tree after the first 100, 50 and 300 burn-in cycles, respectively for CAT, GTR and CAT + GTR. ML runs were performed for 1000 bootstrap iterations under the GTR model of sequence evolution with two parameters for the number of categories defined by a gamma $(\Gamma)$ distribution and the CAT approximation. Under the ML framework, both analyses using the CAT approximation and $\Gamma$ distribution of the rates across sites models yield nearly identical trees, suggesting that the GTR + CAT approximation does not interfere with the outcome of the phylogenetic runs for our dataset. In order to save computing time and power, we therefore opted for the CAT approximation with the GTR model for further tree search analyses under ML. We assessed the effect of missing data on cnidarian phylogenetic relationships in our trees by removing the partial sequences of $C$. americanus and H. coerulea. We also removed the coronate Linuche unguiculata given its problematic position and that it is the only representative of its clade, which could introduce a systematic bias. We then performed additional GTR analyses under the ML framework on the reduced, 103 taxa alignment.

We run jModelTest v2.0.2 [97] on all codon alignments to look for the models that best fit our data. We analyzed all the nucleotide alignments under both the BI framework using PhyloBayes v3.3 and MrBayes v3.2.1 (MB) [98] and ML framework using RAxML v7.2.6 as described above. For PB analyses we use the Q-Matrix Mixture model $(\mathrm{QMM})$ instead of GTR and CAT $+\mathrm{GTR}+\Gamma$. The MB analyses used the GTR $+\Gamma+$ I model of sequence evolution and consisted of two chains of 5,000,000 generations, sampled every 1000 th tree after the $25 \%$ burn-in. 
Table 3 Species list

\begin{tabular}{|c|c|c|c|c|c|c|c|}
\hline Phylum & Subphylum & Class & Subclass & Order & Species & Accession number & Reference \\
\hline \multirow[t]{33}{*}{ Cnidaria } & Anthozoa & Hexacorallia & & Actiniaria & Metridium senile & [GenBank:NC_000933] & {$[68]$} \\
\hline & & & & & Nematostella sp & [GenBank:NC_008164] & [22] \\
\hline & & & & Antipatharia & Chrysopathes formosa & [GenBank:NC_008411] & [39] \\
\hline & & & & & Cirripathes lutkeni & [GenBank:NC_018377] & this study \\
\hline & & & & & Leiopathes glaberrima & [GenBank:FJ597643] \& [GenBank:FJ597644] & [69] \\
\hline & & & & Corallimorpharia & $\underline{\text { Discosoma } \mathrm{sp}}$ & [GenBank:NC_008071] & {$[22]$} \\
\hline & & & & & $\underline{\text { Rhodactis }} \underline{\mathrm{sp}}$ & [GenBank:NC_008158] & [22] \\
\hline & & & & & $\underline{\text { Ricordea florida }}$ & [GenBank:NC_008159] & [22] \\
\hline & & & & Scleractinia & Acropora tenuis & [GenBank:NC_003522] & [70] \\
\hline & & & & & Agaricia humilis & [GenBank:NC_008160] & [22] \\
\hline & & & & & Anacropora matthai & [GenBank:NC_006898] & Unpublishec \\
\hline & & & & & $\underline{\text { Astrangia }} \underline{\mathrm{sp}}$ & [GenBank:NC_008161] & [22] \\
\hline & & & & & Colpophyllia natans & [GenBank:NC_008162] & [22] \\
\hline & & & & & Lophelia pertusa & [GenBank:NC_015143] & [71] \\
\hline & & & & & Madracis mirabilis & [GenBank:NC_011160] & [72] \\
\hline & & & & & Montastraea annularis & [GenBank:NC_007224] & [73] \\
\hline & & & & & Montastraea faveolata & [GenBank:NC_007226] & [73] \\
\hline & & & & & Montastraea franksi & [GenBank:NC_007225] & [73] \\
\hline & & & & & Montipora cactus & [GenBank:NC_006902] & Unpublishec \\
\hline & & & & & Mussa angulosa & [GenBank:NC_008163] & [22] \\
\hline & & & & & Pavona clavus & [GenBank:NC_008165] & [22] \\
\hline & & & & & Pocillopora damicornis & [GenBank:NC_009797] & [74] \\
\hline & & & & & Pocillopora eydouxi & [GenBank:NC_009798] & [74] \\
\hline & & & & & Porites porites & [GenBank:NC_008166] & [22] \\
\hline & & & & & Seriatopora caliendrum & [GenBank:NC_010245] & [72] \\
\hline & & & & & Seriatopora hystrix & [GenBank:NC_010244] & [72] \\
\hline & & & & & Siderastrea radians & [GenBank:NC_008167] & [22] \\
\hline & & & & & Stylophora pistillata & [GenBank:NC_011162] & [72] \\
\hline & & & & Zoantharia & Palythoa sp & [GenBank: DQ640650] & [22] \\
\hline & & & & & $\underline{\text { Savalia savaglia }}$ & [GenBank:NC_008827] & [75] \\
\hline & & & & Ceriantharia & Ceriantheopsis americanus & [GenBank:JX023261-JX023265] & this study \\
\hline & & Octocorallia & & Alcyonacea & Acanella eburnea & [GenBank:NC_011016] & [76] \\
\hline & & & & & Briareum asbestinum & [GenBank:NC_008073] & [22] \\
\hline
\end{tabular}

ublished

[22] 


\begin{tabular}{|c|c|c|c|c|c|c|}
\hline & & & & $\underline{\text { Corallium konojoi }}$ & [GenBank:NC_015406] & [77] \\
\hline & & & & Dendronephthya castanea & [GenBank: GU047877] & [10] \\
\hline & & & & Dendronephthya gigantean & [GenBank:NC_013573] & Unpublished \\
\hline & & & & Dendronephthya mollis & [GenBank: HQ694725] & [10] \\
\hline & & & & Dendronephthya putteri & [GenBank: HQ694726] & [10] \\
\hline & & & & Dendronephthya suensoni & [GenBank: GU047878] & [10] \\
\hline & & & & Echinogorgia complexa & [GenBank: HQ694727] & [10] \\
\hline & & & & Euplexaura crassa & [GenBank: HQ694728] & [10] \\
\hline & & & & Keratoisidinae sp & [GenBank:NC_010764] & [78] \\
\hline & & & & Paracorallium japonicum & [GenBank:NC_015405] & [77] \\
\hline & & & & Pseudopterogorgia bipinnata & [GenBank:NC_008157] & [22] \\
\hline & & & & Sarcophyton glaucum & [GenBank: AF064823] \& [GenBank: AF063191] & {$[79,80]$} \\
\hline & & & & $\underline{\text { Scleronephthya gracillimum }}$ & [GenBank: GU047879] & [10] \\
\hline & & & & Sinularia peculiaris & [GenBank:NC_018379] & this study \\
\hline & & & Helioporacea & Heliopora coerulea & [GenBank:JX023267-JX023272] & this study \\
\hline & & & Pennatulacea & $\underline{\text { Renilla mulleri }}$ & [GenBank:NC_018378] & this study \\
\hline & & & & $\underline{\text { Stylatula elongata }}$ & [GenBank:NC_018380] & this study \\
\hline \multirow[t]{16}{*}{ Medusozoa } & Cubozoa & & Carybdeida & Alatina moseri & [GenBank:JN700951-JN700958] & {$[27]$} \\
\hline & & & & Carukia barnesi & [GenBank:JN700959-JN700962] & {$[27]$} \\
\hline & & & & Carybdea xaymacana & [GenBank:JN700977-JN700983] & {$[27]$} \\
\hline & & & Chirodropida & Chironex fleckeri & [GenBank:JN700963-JN700968] & [27] \\
\hline & & & & Chiropsalmus quadrumanus & [GenBank:JN700969-JN700974] & {$[27]$} \\
\hline & Hydrozoa & Trachylina & Limnomedusae & Cubaia Aphrodite & [GenBank:JN700942] & {$[27]$} \\
\hline & & Hydroidolina & Aplanulata & Ectopleura larynx & [GenBank:JN700938] & {$[27]$} \\
\hline & & & & Hydra magnipapillata & [GenBank:NC_011220] \& [GenBank:NC_01122] & [81] \\
\hline & & & & Hydra oligactis & [GenBank:NC_010214] & [8] \\
\hline & & & & Hydra vulgaris & [GenBank:BN001179] \& [GenBank:BN001180] & [81] \\
\hline & & & Capitata & Millepora platyphylla & [GenBank:JN700943] & [27] \\
\hline & & & & Pennaria tiarella & [GenBank:JN700950] & {$[27]$} \\
\hline & & & Filifera III & Clava multicornis & [GenBank:JN700935] & {$[27]$} \\
\hline & & & Filifera IV & Nemopsis bachei & [GenBank:JN700947] & {$[27]$} \\
\hline & & & Leptothecata & Laomedea flexuosa & [GenBank:JN700945] & [27] \\
\hline & Scyphozoa & & Coronatae & Linuche unguiculata & [GenBank:JN700939] & [27] \\
\hline
\end{tabular}


Table 3 Species list (Continued)

\begin{tabular}{|c|c|c|c|c|c|c|}
\hline & & \multirow[t]{10}{*}{ Discomedusae } & \multirow[t]{4}{*}{ Rhizostomeae } & Cassiopea Andromeda & [GenBank:JN700934] & [27] \\
\hline & & & & Cassiopea frondosa & [GenBank:JN700936] & [27] \\
\hline & & & & Catostylus mosaicus & [GenBank:JN700940] & [27] \\
\hline & & & & Rhizostoma pulmo & [GenBank:JN700987] \& [GenBank:JN700988] & [27] \\
\hline & & & \multirow[t]{6}{*}{ Semaeostomeae } & $\underline{\text { Aurelia aurita } \mathrm{A}}$ & [GenBank:NC_008446] & [11] \\
\hline & & & & 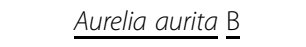 & [GenBank: HQ694729] & [10] \\
\hline & & & & Chrysaora quinquecirrha & [GenBank: HQ694730] & [10] \\
\hline & & & & 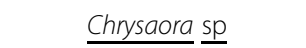 & [GenBank:JN700941] & [27] \\
\hline & & & & Cyanea capillata & [GenBank:JN700937] & [27] \\
\hline & & & & $\underline{P e l a g i a}$ noctiluca & [GenBank:JN700949] & [27] \\
\hline & \multirow[t]{7}{*}{ Staurozoa } & & Stauromedusae & Craterolophus convolvulus & [GenBank:JN700975] \& [GenBank:JN700976] & [27] \\
\hline & & & & $\underline{\text { Haliclystus sanjuanensis }}$ & [GenBank:JN700944] & [27] \\
\hline & & & & Lucernaria janetae & [GenBank:JN700946] & [27] \\
\hline \multirow[t]{4}{*}{ Placozoa } & & & & $\underline{B Z 10101}$ & [GenBank:NC_008832] & [82] \\
\hline & & & & $\underline{B Z 243}$ & [GenBank:NC_008834] & [82] \\
\hline & & & & $\underline{B Z 49}$ & [GenBank:NC_008833] & [82] \\
\hline & & & & Trichoplax adhaerens & [GenBank:NC_008151] & [83] \\
\hline \multirow[t]{16}{*}{ Porifera } & \multirow[t]{4}{*}{ Homoscleromorpha } & & & Corticium candelabrum & [GenBank:NC_014872] & [38] \\
\hline & & & & Oscarella carmela & [GenBank:NC_009090] & [84] \\
\hline & & & & Plakina monolopha & [GenBank:NC_014884] & [38] \\
\hline & & & & Plakinastrella cf. onkodes & [GenBank:NC_010217] & [84] \\
\hline & \multirow[t]{12}{*}{ Demospongiae } & \multirow[t]{2}{*}{$\mathrm{G} 1=$ Keratosa } & & Igernella notabilis & [GenBank:NC_010216] & [84] \\
\hline & & & & Ircinia strobilina & [GenBank:NC_013662] & [85] \\
\hline & & \multirow[t]{3}{*}{ G2 = Myxospongiae } & & Aplysina fulva & [GenBank:NC_010203] & [84] \\
\hline & & & & Chondrilla aff. nucula & [GenBank:NC_010208] & [84] \\
\hline & & & & Halisarca dujardini & [GenBank:NC_010212] & [84] \\
\hline & & \multirow[t]{3}{*}{ G3 = marine Haplosclerida } & & $\underline{\text { Amphimedon compressa }}$ & [GenBank:NC_010201] & [84] \\
\hline & & & & Callyspongia plicifera & [GenBank:NC_010206] & [84] \\
\hline & & & & Xestospongia muta & [GenBank:NC_010211] & [84] \\
\hline & & \multirow[t]{4}{*}{ G4 = Democlavia } & & Agelas schmidti & [GenBank:NC_010213] & [84] \\
\hline & & & & Axinella corrugata & [GenBank:NC_006894] & [84] \\
\hline & & & & Cinachyrella kuekanthali & [GenBank:NC_010198] & [84] \\
\hline & & & & Ephydatia muelleri & [GenBank:NC_010202] & [84] \\
\hline
\end{tabular}


Table 3 Species list (Continued)

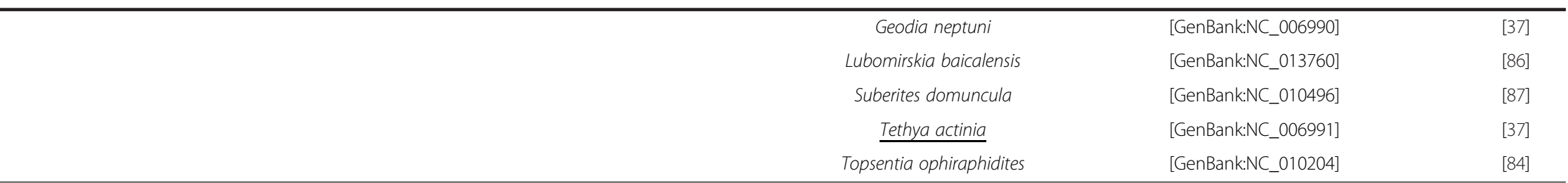

List of species, with their accession number and reference, used for this studies. Bold species are from this study. Underline species are those included into the codon alignments. 


\section{Evaluating phylogenetic inferences}

We tested several relationships that had been earlier hypothesized with the amino acid dataset under ML by calculating the per-site log likelihood values with RAxML v7.2.6 under the GTR model. We then used three commonly used tests (the Approximately Unbiased (AU) test, the Kishino-Hasegawa (KH) test, and the ShimodairaHasegawa ( $\mathrm{SH}$ ) test) to assess the validity of several key phylogenetic relationships according to our data. To do so, we compared whether our data significantly rejected the best trees conforming to each of the a priori hypotheses (Table 2) using the CONSEL software [99].

For Bayesian inferences, a cross-validation was performed to find the model with the best fit to the data. Each alignment is randomly split in two unequal parts: a "learning dataset" with nine-tenth of the original positions and a "testing dataset" with one-tenth; ten replicates are performed. The parameters of the model are estimated on the learning datasets for each model (fixed topology inferred with the CATGTR model; 11,000 cycles; the first 1,000 cycles removed) and therefore used to calculate the cross-validation log-likelihood scores of the test datasets, averaged over the ten replicates.

Finally, we sampled ten important morphological characters from previously published morphological matrices $[18,28,58,100]$ and mapped them on the CATGTR based tree. To do so we used PAUP 4.0b10 for Unix [101] using DELTRAN and ACCRAN character-state optimization models. The scoring of each character is detailed in additional materials (Additional file 7).

\section{Additional files}

Additional file 1: Figure S1. Cnidarian phylogeny of mitochondrial protein genes using the reduced alignment AliMGred with 103 species. Phylogenetic analyses of cnidarian protein coding genes under the GTR model and CAT approximation with RAxML for the reduced AliMG alignment (AliMGred), where the coronate Linuche unguiculata, the tube anemone Ceriantheopsis americanus and the blue octocoral Heliopora coerulea were removed. Node supports correspond to the bootstraps values. Stars denote maximum support values. 1: Zoantharia; 2: Actiniaria; 3: Antipatharia; 4: Corallimorpharia; 5: Scleractinia; 6: Alcyonacea; 7: Pennatulacea; 8: Stauromedusae; 9: Carybdeida; 10: Chirodropida; 11: Limnomedusae; 12: Filifera III; 13: Filifera IV; 14: Leptothecata; 15: Capitata; 16: Aplanulata; 17: Semaeostomeae; 18: Rhizostomeae.

Additional file 2: Figure S2. Cnidarian phylogeny of mitochondrial protein genes using the codon alignment CodAliM75tx-argleuser3. Phylogenetic analyses of cnidarian protein coding genes under the $\mathrm{QMM}+\Gamma$ model with PhyloBayes for the CodAliM75tx-argleuser3 alignments (4785 parsimony-informative characters). Support values correspond to the posterior probabilities for the QMM, the GTR(BI) and bootstraps for GTR(ML) analyses, respectively. Stars denote support values of $\mathrm{PP}>0.98$ and $\mathrm{BV}>95$. A dash denotes discrepancy between the results obtained by different methods. 1: Zoantharia; 2: Actiniaria; 3: Antipatharia; 4: Corallimorpharia; 5: Scleractinia; 6: Alcyonacea; 7: Pennatulacea; 8: Stauromedusae; 9: Carybdeida; 10: Chirodropida; 11: Limnomedusae; 12: Filifera III; 13: Filifera IV; 14: Leptothecata;
15: Capitata; 16: Aplanulata; 17: Semaeostomeae; 18: Rhizostomeae; 19: Ceriantharia; 20: Helioporacea.

Additional file 3: Figure S3. Cnidarian phylogeny of mitochondrial protein genes using the codon alignment CodAliM75tx-ser3. Phylogenetic analyses of cnidarian protein coding genes under the $\mathrm{QMM}+\lceil$ model with PhyloBayes for the CodAliM75tx-ser3 alignments (5318 parsimony-informative characters). Support values correspond to the posterior probabilities for QMM and GTR(BI) and bootstraps for GTR (ML) analyses, respectively. A star denotes support values of PP $>0.98$ and $B V>95$. A dash denotes discrepancy between the results obtained by different methods. 1: Zoantharia; 2: Actiniaria; 3: Antipatharia;

4: Corallimorpharia; 5: Scleractinia; 6: Alcyonacea; 7: Pennatulacea; 8: Stauromedusae; 9: Carybdeida; 10: Chirodropida; 11: Limnomedusae; 12: Filifera III; 13: Filifera IV; 14: Leptothecata; 15: Capitata; 16: Aplanulata; 17: Semaeostomeae; 18: Rhizostomeae; 19: Ceriantharia; 20: Helioporacea.

Additional file 4: Figure S4. The use of several statistical tests verifying the validity of some groups in cnidarians for the reduced alignment AliMGred. Probability values for the $\mathrm{AU}, \mathrm{KH}$ and $\mathrm{SH}$ tests and $\mathrm{BI}$ values for several clades traditionally recognized in Cnidaria for the reduced alignment AliMGred containing 103 species, where the coronate Linuche unguiculata, the tube anemone Ceriantheopsis americanus and the blue octocoral Heliopora coerulea were removed.

Additional file 5: Figure S5. Composition of the amino acid alignment used in this study. Principal component analysis of the amino acid composition per species for the amino acid alignment AliMG used in this study. Species have been color-coded per group corresponding to each of the main cnidarian clades (Coronatae, Cubozoa, Discomedusa, Hexacorallia, Hydrozoa, Octocorallia, and Staurozoa), Porifera and Placozoa. The axes explain 33 and 22 per cent of the data.

Additional file 6: Figure S6. Alignment AliMG. Alignments AliMG (3485 positions, 106 taxa) created using the combination MUSCLE + Gblocks.

Additional file 7: Figure S7. Table of morphological characters mapped on the best tree. Mapping of morphological characters under DELTRAN and ACCTRAN models differed only for characters (5) and (7).

(1) symmetry: medusozoan taxa have been scored radial, but Marques and Collins (2004) subdivided it into radial, biradial, or radial tetramerous; Octocorallia, Zoantharia and Ceriantharia are scored bilateral (Won et al. 2001), while the remnant of Hexacorallia was scored radial (Marques and Collins 2004); bilaterial symmetry is inferred the ancestral state for Cnidaira. (2) free-swimming medusoid stage: Hexa-, Octocorallia and Staurozoa all lack a free-living adult form (Marques and Collins 2004); the medusoid stage is also lacking in some Hydrozoa species but Collins (2002) and Cartwright and Nawrocki (2010) have inferred that the ancestral Hydrozoa had a medusoid stage. (3) velum: only present in Hydrozoa (Marques and Collins 2004). (4) strobilation: only described in Coronatae and Discomedusae (Marques and Collins 2004). (5) gastric filaments: we scored them as present in Cubozoa (Brigde et al. 1995), Staurozoa, Coronatae and Discomedusae (Marques and Collins 2004), and absent in Hydrozoa (Brigde et al. 1995), although suggested to be present in some Aplanulata (Bouillon et al. 2004); we decided to opt for the most parsimonious scenario. (6) ephyrae: only described in Coronatae and Discomedusae (Marques and Collins 2004). (7) radial canals:

described in Coronatae, Discomedusae, and some Hydrozoa, absent in Staurozoa and unresolved in Cubozoa (Marques and Collins 2004); we choose two independent gains in Coronatae and Discomedusae as the most parsimonious scenario. (8) circular canals: present in Discomedusae and Hydrozoa, absent in the rest of Medusozoa. Marques and Collins (2004) have further distinguished the level of development of these structures that are partial in Discomedusae and full in Hydrozoa. (9) quadrate symmetry of horizontal cross section: present only in Cubozoa and Staurozoa (Marques and Collins 2004). (10) organization of the gastrodermal muscles of the polyp: organized in bunches of gastrodermic origin in all Hexacorallia but Ceriantharia, and inferred as the ancestral state for Cnidaria; organized in bunches of epidermic origin in all Medusozoa but Hydrozoa. In Hydrozoa and Ceriantharia, gastrodermal muscle are not organized in bunches (Marques and Collins 2004). 


\section{Competing interests}

The authors declare that they have no competing interests.

\section{Authors' contributions}

EK participated in the design of the study, carried out $\mathrm{ML}$ and $\mathrm{BI}$ phylogenetic analyses and statistical tests, reconstructed the evolution of morphological characters, and drafted the manuscript. BR carried out some of the PB phylogenetic analyses and extracted the support values, performed the cross validation. HP and DL helped in the design of the study. AGC provided guidance on some analyses and the interpretation of the morphological characters. All authors contributed to the final version of the manuscript.

\section{Acknowledgements}

We would like to thank Matthew Palen for his wonderful drawings of cnidarians. We would also like to thank Niamh Redmond and Henner Brinkmann for their highly insightful comments on this manuscript. We also want to thank Omar Rota Stabelli, Corrinne Grover and Emmanuel Szadkowski for their help with the construction of the nucleotide alignments and analyses. This work was supported by a grant from the National Science Foundation to DVL [DEB-0829783] and by funding from lowa State University. EK wishes to acknowledge funding through the Smithsonian Predoctoral Fellow grant. Some samples used in this study came from work supported by the NSF-funded Cnidarian Tree of Life Project (EF-0531779 to P. Cartwright, D. Fautin and AGC).

\section{Author details}

${ }^{1}$ Dept. Ecology, Evolution, and Organismal Biology, lowa State University, Ames, lowa 50011, USA. ²Department of Invertebrate Zoology, National Museum of Natural History, Smithsonian Institution, Washington, DC 20013-7012, USA. ³ Dept. Biochimie, Fac. Médecine, Université de Montral, Pavillon Roger-Gaudry, C.P. 6128, Succ. Centre-Ville, Montral, QC H3C 3J7, Canada. ${ }^{4}$ National Systematics Laboratory of NOAA's Fisheries Service, National Museum of Natural History, MRC-153, Smithsonian Institution, PO Box 37012, Washington, DC 20013-7012, USA.

Received: 16 May 2012 Accepted: 21 December 2012 Published: 9 January 2013

\section{References}

1. Daly M, Brugler MR, Cartwright P, Collins AG, Dawson MN, Fautin DG, France SC, Mcfadden CS, Opresko DM, Rodriguez E, Romano SL, Stake JL: The phylum Cnidaria: A review of phylogenetic patterns and diversity 300 years after Linnaeus*. Zootaxa 2007, 182:127-128.

2. Collins AG: Recent insights into cnidarian phylogeny. Smithsonian Contributions to Marine Sciences 2009, 38:139-149.

3. Cavalier-Smith T, Allsopp MTEP, Chao EE, Boury-Esnault N, Vacelet J: Sponge phylogeny, animal monophyly, and the origin of the nervous system: 18 S rRNA evidence. Can J Zool 1996, 74:2031-2045.

4. France SC, Rosel PE, Agenbroad JE, Mullineaux LS, Kocher T: DNA sequence variation of mitochondrial large-subunit rRNA provides support for a two-subclass organization of the Anthozoa (Cnidaria). Mol. Mar. Biol. Biotechnolog 1996, 5:15-28.

5. Odorico DM, Miller DJ: Internal and external relationships of the Cnidaria: implications of primary and predicted secondary structure of the $5^{\prime}$-end of the 23S-like rDNA. Proc Biol Sci/R. Soc 1997, 264:77-82.

6. Berntson EA, France SC, Mullineaux LS: Phylogenetic relationships within the class Anthozoa (phylum Cnidaria) based on nuclear 18S rDNA sequences. Mol Phylogenet Evol 1999, 13:417-433.

7. Collins AG: Phylogeny of Medusozoa and the evolution of cnidarian life cycles. J Evolution Biol 2002, 15:418-432.

8. Kayal E, Lavrov DV: The mitochondrial genome of Hydra oligactis (Cnidaria, Hydrozoa) sheds new light on animal mtDNA evolution and cnidarian phylogeny. Gene 2008, 410:177-186.

9. Lavrov DV, Wang X, Kelly M: Reconstructing ordinal relationships in the Demospongiae using mitochondrial genomic data. Mol Phylogenet Evol 2008, 49:111-124.

10. Park E, Hwang D-S, Lee J-S, Song J-I, Seo T-K, Won Y-J: Estimation of divergence times in cnidarian evolution based on mitochondrial proteincoding genes and the fossil record. Mol Phylogenet Evol 2012, 62:329-345.
11. Shao Z, Graf S, Chaga OY, Lavrov DV: Mitochondrial genome of the moon jelly Aurelia aurita (Cnidaria, Scyphozoa): A linear DNA molecule encoding a putative DNA-dependent DNA polymerase. Gene 2006, 381:92-101.

12. Kim J, Kim W, Cunningham CW: A new perspective on lower metazoan relationships from 18S rDNA Sequences. Mol Biol Evol 1999, 16:423-427.

13. Dawson MN: Some implications of molecular phylogenetics for understanding biodiversity in jellyfishes, with emphasis on Scyphozoa. Hydrobiologia 2004, 530-531:249-260.

14. Collins AG, Schuchert P, Marques AC, Jankowski T, Medina M, Schierwater B: Medusozoan phylogeny and character evolution clarified by new large and small subunit rDNA data and an assessment of the utility of phylogenetic mixture models. Syst Bio 2006, 55:97-115.

15. Mayer AG: Medusae of the world. Washington, D.C: Carnegie institution of Washington; 1910:386.

16. Thiel H: The evolution of Scyphozoa: A review. In Cnidaria and their Evolution. London: Academic Press; 1966.

17. Bayha KM, Dawson MN, Collins AG, Barbeitos MS, Haddock SHD: Evolutionary relationships among scyphozoan jellyfish families based on complete taxon sampling and phylogenetic analyses of $18 \mathrm{~S}$ and $28 \mathrm{~S}$ ribosomal DNA. Integr Comp Biol 2010, 50:436-455.

18. Cartwright $P$, Nawrocki AM: Character evolution in hydrozoa (phylum Cnidaria). Integr Comp Biol 2010, 50(3):456-472.

19. Cartwright $P$, Evans NM, Dunn CW, Marques AC, Miglietta MP, Schuchert $P$, Collins AG: Phylogenetics of Hydroidolina (Hydrozoa: Cnidaria). J. Mar. Biol. Assoc. U.K 2008, 88:1663-1672.

20. Kitahara MV, Cairns SD, Stolarski J, Blair D, Miller DJ: A comprehensive phylogenetic analysis of the Scleractinia (Cnidaria, Anthozoa) based on mitochondrial CO1 sequence data. PLoS One 2010, 5:e11490.

21. Fukami H, Chen CA, Budd AF, Collins A, Wallace C, Chuang Y-Y, Chen C, Dai C-F, Iwao K, Sheppard C, Knowlton N: Mitochondrial and nuclear genes suggest that stony corals are monophyletic but most families of stony corals are not (Order Scleractinia, Class Anthozoa, Phylum Cnidaria). PLoS One 2008, 3:e3222.

22. Medina M, Collins AG, Takaoka TL, Kuehl JV, Boore JL: Naked corals: skeleton loss in Scleractinia. Proc Nat Acad Sci USA 2006, 103:9096-9100.

23. Bentlage B, Cartwright P, Yanagihara AA, Lewis C, Richards GS, Collins AG: Evolution of box jellyfish (Cnidaria: Cubozoa), a group of highly toxic invertebrates. Proc Bio/ Sci/R Soc 2010, 277:493-501.

24. McFadden CS, Sanchez JA, France SC: Molecular phylogenetic insights into the evolution of octocorallia: a review. Integr Comp Biol 2010, 50:389-410.

25. Barbeitos MS, Romano SL, Lasker HR: Repeated loss of coloniality and symbiosis in scleractinian corals. Proc Nat Acad Sci USA 2010, 107:11877-11882.

26. Costello JH, Colin SP, Dabiri JO: Medusan morphospace: phylogenetic constraints, biomechanical solutions, and ecological consequences. Invertebr Biol 2008, 127:265-290.

27. Kayal E, Bentlage B, Collins AG, Kayal M, Pirro S, Lavrov DV: Evolution of linear mitochondrial genomes in medusozoan cnidarians. Genome Biol Evol 2012, 4:1-12.

28. Marques AC, Collins AG: Cladistic analysis of Medusozoa and cnidarian evolution. Invertebr Biol 2004, 123:23-42.

29. Collins AG, Bentlage B, Lindner A, Lindsay D, Haddock SHD, Jarms G, Norenburg $J$, Jankowski T, Cartwright P: Phylogenetics of Trachylina (Cnidaria: Hydrozoa) with new insights on the evolution of some problematical taxa. J Mar Biol Assoc U.K 2008, 88:1673-1685.

30. Leclère L, Schuchert P, Cruaud C, Couloux A, Manuel M: Molecular phylogenetics of Thecata (Hydrozoa, Cnidaria) reveals long-term maintenance of life history traits despite high frequency of recent character changes. Syst Biol 2009, 58:509-526.

31. Leclère $L$, Schuchert $P$, Manuel M: Phylogeny of the Plumularioidea (Hydrozoa, Leptothecata): evolution of colonial organisation and life cycle. Zoologica Scripta 2007, 36:371-394.

32. Kan X-Z, Yang J-K, Li X-F, Chen L, Lei Z-P, Wang M, Qian C-J, Gao H, Yang Z-Y: Phylogeny of major lineages of galliform birds (Aves: Galliformes) based on complete mitochondrial genomes. Genet Mol Res: GMR 2010, 9(3):1625-1633.

33. Podsiadlowski L, Braband A, Struck TH, Von Döhren J, Bartolomaeus T: Phylogeny and mitochondrial gene order variation in Lophotrochozoa in the light of new mitogenomic data from Nemertea. BMC Genomics 2009, $10: 364$. 
34. Rota-Stabelli O, Kayal E, Gleeson D, Daub J, Boore JL, Telford MJ, Pisani D, Blaxter M, Lavrov DV: Ecdysozoan mitogenomics: evidence for a common origin of the legged invertebrates, the panarthropoda. Genome Biol Evol 2010, 2:425-440.

35. Hoelzer GA: Inferring phylogenies from mtDNA variation: mitochondrialgene trees versus nuclear-gene trees revisited. Evolution 1997, 51:622-626.

36. Boore $\mathrm{J}$, Fuerstenberg SI: Beyond linear sequence comparisons: the use of genome-level characters for phylogenetic reconstruction. Philosophical transactions of the Royal Society of London. Series B, Biol Sci 2008, 363:1445-1451.

37. Lavrov DV, Forget L, Kelly M, Lang BF: Mitochondrial genomes of two demosponges provide insights into an early stage of animal evolution. Mol Biol Evol 2005, 22:1231-1239.

38. Gazave E, Lapébie P, Renard E, Vacelet J, Rocher C, Ereskovsky AV, Lavrov DV, Borchiellini C: Molecular phylogeny restores the supra-generic subdivision of homoscleromorph sponges (Porifera, Homoscleromorpha). PLoS One 2010, 5:e14290.

39. Brugler MR, France SC: The complete mitochondrial genome of the black coral Chrysopathes formosa (Cnidaria: Anthozoa: Antipatharia) supports classification of antipatharians within the subclass Hexacorallia. Mol Phylogenet Evol 2007, 42:776-788.

40. Pick KS, Philippe H, Schreiber F, Erpenbeck D, Jackson DJ, Wrede P, Wiens M, Alié A, Morgenstern B, Manuel M, Wörheide G: Improved phylogenomic taxon sampling noticeably affects nonbilaterian relationships. Mol Biol Evol 2010, 27:1983-1987.

41. Philippe H, Brinkmann H, Lavrov DV, Littlewood DTJ, Manuel M, Wörheide $G$, Baurain D: Resolving difficult phylogenetic questions: why more sequences are not enough. PLOS Biol 2011, 9:e1000602.

42. Philippe H, Zhou Y, Brinkmann H, Rodrigue N, Delsuc F: Heterotachy and long-branch attraction in phylogenetics. BMC Evol Biol 2005, 5:50.

43. Roure BB, Philippe $H H$ : Site-specific time heterogeneity of the substitution process and its impact on phylogenetic inference. BMC Evol Biol 2011, $11: 17$.

44. Stabelli OR, Lartillot N, Philippe H, Pisani D: Serine codon usage bias in deep phylogenomics: pancrustacean relationships as a case study. Syst Biol 2012, doi:10.1093/sysbio/sys077.

45. Zrzavy J, Mihulka S, Kepka P, Bezdek A, Tietz D: Phylogeny of the Metazoa Based on Morphological and 18S Ribosomal DNA Evidence. Cladistics 1998, 14:249-285.

46. Siddall ME, Martin DS, Bridge D, Desser SS, David K, Martint DS, Bridget D, Conell DK: The demise of a phylum of protists: phylogeny of myxozoa and other parasitic cnidaria. J Parasito/ 1995, 81:961-967.

47. Schuchert P: Phylogenetic analysis of the Cnidaria. J. Zoolog. Syst. Evol. Res 1993, 31:161-173.

48. Evans NM, Holder MT, Barbeitos MS, Okamura B, Cartwright P: The phylogenetic position of myxozoa: exploring conflicting signals in phylogenomic and ribosomal datasets. Mol Biol 2010, 8:139.

49. Evans NM, Lindner A, Raikova EV, Collins AG, Cartwright P: Phylogenetic placement of the enigmatic parasite, Polypodium hydriforme, within the Phylum Cnidaria. BMC Evol Biol 2008, 8:139.

50. Lartillot $\mathrm{N}$, Brinkmann $\mathrm{H}$, Philippe $\mathrm{H}$ : Suppression of long-branch attraction artefacts in the animal phylogeny using a site-heterogeneous model. BMC Evol Biol 2007, 7(Suppl 1):S4.

51. Collins AG, Winkelmann S, Hadrys H, Schierwater B: Phylogeny of Capitata and Corynidae (Cnidaria, Hydrozoa) in light of mitochondrial 16S rDNA data. Zoologica Scripta 2005, 34:91-99.

52. Budd AF, Romano SL, Smith ND, Barbeitos MS: Rethinking the phylogeny of scleractinian corals: a review of morphological and molecular data. Integr Comp Biol 2010, 50:411-427.

53. McFadden CS, Benayahu Y, Pante E, Thoma JN, Nevarez AP, France SC: Limitations of mitochondrial gene barcoding in Octocorallia. Mol Ecol Res 2011, 11:19-31.

54. Bilewitch JP, Degnan SM: A unique horizontal gene transfer event has provided the octocoral mitochondrial genome with an active mismatch repair gene that has potential for an unusual self-contained function. BMC Evol Biol 2011, 11:228.

55. McFadden CS, France SC, Sánchez JA, Alderslade P: A molecular phylogenetic analysis of the Octocorallia (Cnidaria: Anthozoa) based on mitochondrial protein-coding sequences. Mol Phylogenet Evol 2006, 41:513-27.
56. Finnerty JR, Pang K, Burton P, Paulson D, Martindale MQ: Origins of bilateral symmetry: Hox and dpp expression in a sea anemone. Science 2004, 304:1335-1337.

57. Matus DQ, Pang K, Marlow H, Dunn CW, Thomsen GH, Martindale MQ Molecular evidence for deep evolutionary roots of bilaterality in animal development. Proc Nat Acad Sci USA 2006, 103:11195-11200.

58. Van Iten H, De Moraes $\sqcup$, Simões MG, Marques AC, Collins AG: Reassessment of the phylogenetic position of conulariids (?Ediacaran--Triassic) within the subphylum medusozoa (phylum cnidaria). J Syst Palaeontol 2006, 4:109-118.

59. Dunn CW: Complex colony-level organization of the deep-sea siphonophore Bargmannia elongata (Cnidaria, Hydrozoa) is directionally asymmetric and arises by the subdivision of pro-buds. Dev. Dyn: an official publication of the American Association of Anatomists 2005 234:835-845.

60. Jiménez-Guri E, Philippe H, Okamura B, Holland PWH: Buddenbrockia is a cnidarian worm. Science (New York, N.Y.) 2007, 317:116-118.

61. Palmer RA: Symmetry breaking and the evolution of development. Science 2004, 306:828-833.

62. Levin M: Left-right asymmetry in embryonic development: a comprehensive review. Mech Develop 2005, 122:3-25.

63. Nielsen C: Six major steps in animal evolution: are we derived sponge larvae? Evol Develop 2008, 10:241-257.

64. Uchida T: The systematic position of the Stauromedusae. Pub/ Seto Mar Biol Lab 1972, 20:133-139.

65. Werner B: New investigations on systematics and evolution of the class Scyphozoa and the phylum Cnidaria. Publ Seto Mar Biol Lab 1973, 20:35-61.

66. Gibbons MJ, Janson LA, Ismail A, Samaai T: Life cycle strategy, species richness and distribution in marine Hydrozoa (Cnidaria: Medusozoa). J Biogeogr 2010, 37:441-448.

67. Boero F, Schierwater B, Piraino S: Cnidarian milestones in metazoan evolution. Integr Comp Biol 2007, 47:693-700.

68. Beagley $C T$, Okimoto $R$, Wolstenholme DR: The mitochondrial genome of the sea anemone Metridium senile (Cnidaria): introns, a paucity of tRNA genes, and a near-standard genetic code. Genetics 1998, 148:1091-1108.

69. Sinniger F, Pawlowski J: The partial mitochondrial genome of Leiopathes glaberrima (Hexacorallia: Antipatharia) and the first report of the presence of an intron in COI in black corals. Galaxea, $J$ Coral Reef Studies 2009, 11(1):21-26.

70. Van Oppen MJH, Catmull J, McDonald BJ, Hislop NR, Hagerman PJ, Miller DJ: The mitochondrial genome of Acropora tenuis (Cnidaria; Scleractinia) contains a large group I intron and a candidate control region. J Mol Evol 2002, 55:1-13.

71. Emblem Å, Karlsen BO, Evertsen J, Johansen SD: Mitogenome rearrangement in the cold-water scleractinian coral Lophelia pertusa (Cnidaria, Anthozoa) involves a long-term evolving group I intron. Mol Phylogenet Evol. 2011, 61:495-503.

72. Chen C, Chiou C-Y, Dai C-F, Chen CA: Unique mitogenomic features in the scleractinian family pocilloporidae (scleractinia: astrocoeniina). Marine Biotechnology 2008, 10:538-553.

73. Fukami $\mathrm{H}$, Knowlton N: Analysis of complete mitochondrial DNA sequences of three members of the Montastraea annularis coral species complex (Cnidaria, Anthozoa, Scleractinia). Coral Reefs 2005, 24:410-417.

74. Flot J-F, Tillier S: The mitochondrial genome of Pocillopora (Cnidaria: Scleractinia) contains two variable regions: the putative D-loop and a novel ORF of unknown function. Gene 2007, 401(1-2):80-87.

75. Sinniger $F$, Chevaldonné P, Pawlowski J: Mitochondrial genome of Savalia savaglia (Cnidaria, Hexacorallia) and early metazoan phylogeny. J. Mol. Evol 2007, 64:196-203.

76. Van der Ham JL, Brugler MR, France SC: Exploring the utility of an indelrich, mitochondrial intergenic region as a molecular barcode for bamboo corals (Octocorallia: Isididae). Marine Genomics 2009, 2(3-4):183-192.

77. Uda K, Komeda Y, Koyama H, Koga K, Fujita T, Iwasaki N, Suzuki T: Complete mitochondrial genomes of two Japanese precious corals, Paracorallium japonicum and Corallium konojoi (Cnidaria, Octocorallia, Coralliidae): Notable differences in gene arrangement. Gene 2011, 476:27-37.

78. Brugler MR, France SC: The mitochondrial genome of a deep-sea bamboo coral (Cnidaria, Anthozoa, Octocorallia, Isididae): genome structure and 
putative origins of replication are not conserved among octocorals. J Mol Evol 2008, 67:125-136.

79. Beaton MJ, Roger a J, Cavalier-Smith T: Sequence analysis of the mitochondrial genome of Sarcophyton glaucum: conserved gene order among octocorals. J Mol Evol 1998, 47:697-708.

80. Pont-Kingdon G, Okada NA, Macfarlane $J$, Beagley $C T$, Watkins-Sims $C D$, Cavalier-Smith T, Clark-Walker GD, Wolstenholme DR: Mitochondrial DNA of the coral Sarcophyton glaucum contains a gene for a homologue of bacterial MutS: a possible case of gene transfer from the nucleus to the mitochondrion. J Mol Evol 1998, 46:419-431.

81. Voigt O, Erpenbeck D, Wörheide G: A fragmented metazoan organellar genome: the two mitochondrial chromosomes of Hydra magnipapillata. BMC genomics 2008, 9:350.

82. Signorovitch AY, Buss LW, Dellaporta SL: Comparative genomics of large mitochondria in placozoans. PLoS Genetics 2007, 3(1):e13.

83. Dellaporta SL, Xu A, Sagasser S, Jakob W, Moreno MA, Buss LW, Schierwater B: Mitochondrial genome of Trichoplax adhaerens supports Placozoa as the basal lower metazoan phylum. Proc Natl Acad Sci 2006, 103:8751-8756.

84. Wang $X$, Lavrov DV: Seventeen new complete mtDNA sequences reveal extensive mitochondrial genome evolution within the demospongiae. PLOS ONE 2008, 3:e2723.

85. Erpenbeck D, Voigt O, Wörheide G, Lavrov DV: The mitochondrial genomes of sponges provide evidence for multiple invasions by Repetitive Hairpin-forming Elements (RHE). BMC genomics 2009, 10:591.

86. Lavrov DV: Rapid proliferation of repetitive palindromic elements in $\mathrm{mtDNA}$ of the endemic Baikalian sponge Lubomirskia baicalensis. Mol Biol Evol 2010, 27:757-760.

87. Lukić-Bilela L, Brandt D, Pojskić N, Wiens M, Gamulin V, Müller WEG: Mitochondrial genome of Suberites domuncula: palindromes and inverted repeats are abundant in non-coding regions. Gene 2008, 412:1-11.

88. Drummond A, Ashton B, Buxton S, Cheung M, Cooper A, Duran C, Field M, Heled J, Kearse M, Markowitz S, Moir R, Stones-Havas S, Sturrock S, Thierer T, Wilson A: Geneious Pro v5.5.6. 2011.

89. Suyama M, Torrents D, Bork P: PAL2NAL: robust conversion of protein sequence alignments into the corresponding codon alignments. Nucleic Acids Res 2006, 34:W609-W612.

90. Philippe H: MUST, a computer package of Management Utilities for Sequences and Trees. Nucleic Acids Res 1993, 21:5264-5272.

91. Lartillot N, Philippe H: Computing Bayes factors using thermodynamic integration. Syst Bio 2006, 55:195-207.

92. Lartillot N, Philippe H: A Bayesian mixture model for across-site heterogeneities in the amino-acid replacement process. Mol Biol Evol 2004, 21:1095-1109.

93. Ott M, Zola J, Stamatakis A: Large-scale maximum likelihood-based phylogenetic analysis on the IBM BlueGene/L. In Proceedings of ACM/IEEE Supercomputing Conference. 2007. 2007.

94. Stamatakis A: RAxML-VI-HPC: maximum likelihood-based phylogenetic analyses with thousands of taxa and mixed models. Bioinformatics (Oxford, England) 2006, 22:2688-2690.

95. Stamatakis A: Phylogenetic models of rate heterogeneity: a high performance computing perspective. Proceedings 20th IEEE International Parallel \& Distributed Processing Symposium 2006, :8.

96. Stamatakis A, Hoover P, Rougemont J: A rapid bootstrap algorithm for the RAxML Web servers. Syst Biol 2008, 57:758-771.

97. Posada D: jModelTest: phylogenetic model averaging. Mol Biol Evol 2008, 25:1253-1256

98. Ronquist F, Teslenko M, Van der Mark P, Ayres DL, Darling A, Höhna S, Larget B, Liu L, Suchard MA, Huelsenbeck JP: MrBayes 3.2: efficient Bayesian phylogenetic inference and model choice across a large model space. Syst Biol 2012, 61:539-542.

99. Shimodaira H, Hasegawa M: CONSEL: for assessing the confidence of phylogenetic tree selection. Bioinformatics (Oxford, England) 2001, 17:1246-1247.

100. Won J, Rho B, Song J: A phylogenetic study of the Anthozoa (phylum Cnidaria) based on morphological and molecular characters. Coral Reefs 2001, 20:39-50.

101. Swofford DL: PAUP* 4.0. 2002, 42:1-144.

\section{Submit your next manuscript to BioMed Central and take full advantage of:}

- Convenient online submission

- Thorough peer review

- No space constraints or color figure charges

- Immediate publication on acceptance

- Inclusion in PubMed, CAS, Scopus and Google Scholar

- Research which is freely available for redistribution 